\title{
openheart Secondary prevention and outcomes in outpatients with coronary artery disease, atrial fibrillation or heart failure: a focus on disease overlap
}

\author{
Nicolas Lamblin, ${ }^{1}$ Sandro Ninni, ${ }^{1}$ Olivier Tricot, ${ }^{2}$ Thibaud Meurice, ${ }^{3}$ Gilles Lemesle, ${ }^{1}$ \\ Christophe Bauters (iD ${ }^{1}$
}

\begin{abstract}
- Additional material is published online only. To view please visit the journal online (http://dx.doi.org/10.1136/ openhrt-2019-001165).
\end{abstract}

To cite: Lamblin N, Ninni S, Tricot 0 , et al. Secondary prevention and outcomes in outpatients with coronary artery disease, atrial fibrillation or heart failure: a focus on disease overlap. Open Heart 2020;7:e001165. doi:10.1136/ openhrt-2019-001165

Received 6 September 2019 Revised 14 February 2020 Accepted 26 March 2020
Check for updates

C Author(s) (or their employer(s)) 2020. Re-use permitted under CC BY-NC. No commercial re-use. See rights and permissions. Published by BMJ.

${ }^{1}$ Department of Cardiology, Université de Lille, Lille, France 2Department of Cardiology, Centre Hospitalier de Dunkerque, Dunkerque, France ${ }^{3}$ Department of Cardiology, Hôpital Privé Le Bois, Lille, France

Correspondence to Dr Christophe Bauters; christophe.bauters@chru-lille.fr

\section{ABSTRACT}

Objective To assess secondary prevention and outcomes in patients with chronic coronary artery disease (CAD), atrial fibrillation (AF) and heart failure (HF), focusing on disease overlap.

Methods We analysed the data of 10517 outpatients with a diagnosis of $\mathrm{CAD}, \mathrm{AF}$ and/or HF included in a prospective cohort study. Follow-up (median 3.2 years) was achieved in 10478 (99.6\%) patients. Seven mutually exclusive patient groups were formed: $C A D$ alone $(n=4303), A F$ alone $(n=2604), C A D+A F(n=700), H F$ alone $(n=513), H F+C A D$ $(n=728), H F+A F(n=1087)$ and $H F+C A D+A F(n=582)$.

Results Patients with disease overlaps represented $29.4 \%$ of the total population. The level of secondary prevention was high in all subgroups and in accordance with European class I - level A guidelines. Among patients with $\mathrm{CAD}, 99 \%$ received an antithrombotic and $91 \%$ received a statin. Among patients with $\mathrm{AF}$, $81.7 \%$ were treated with an anticoagulant if indicated. Among HF patients with left ventricular ejection fraction $<40 \%, 90.9 \%$ received a renin-angiotensin system antagonist and $91 \%$ a beta-blocker. Three-year all cause/ cardiovascular mortality rates were: $6.4 \% / 2 \%, 9.7 \% / 3.3 \%$, $15.6 \% / 6.7 \%, 19.2 \% / 9.4 \%, 24.3 \% / 13.6 \%, 28 \% / 15.7 \%$ and $35.4 \% / 24.8 \%$, for patients with $\mathrm{CAD}$ alone, $\mathrm{AF}$ alone, $\mathrm{CAD}+\mathrm{AF}, \mathrm{HF}$ alone, $\mathrm{HF}+\mathrm{CAD}, \mathrm{HF}+\mathrm{AF}$ and $\mathrm{HF}+\mathrm{CAD}+\mathrm{AF}$, respectively. In all groups with $\mathrm{HF}$, observed all-cause mortality was higher $(p<0.0001)$ than expected mortality for age-matched, gender-matched and geographymatched persons. In contrast, observed mortality was lower than expected for patients with $\mathrm{CAD}$ alone and $\mathrm{AF}$ alone $(p<0.0001)$.

Conclusions In a context of adequate secondary prevention, overlap between diseases is a frequent and high-risk situation with incremental increases in mortality. These patients deserve specific attention.

\section{INTRODUCTION}

Coronary artery disease (CAD), atrial fibrillation $(\mathrm{AF})$ and heart failure (HF) are three extremely common cardiovascular diseases for which management is regularly updated by international guidelines. ${ }^{1-3}$ Guidelineguided secondary prevention strategies are

\section{Key questions}

What is already known about this subject?

- Observational studies have provided information on secondary prevention and outcomes in patients with coronary artery disease, atrial fibrillation or heart failure, separately.

What does this study add?

The study shows that overlap between the three diseases is relatively frequent in an outpatient setting. In spite of adequate secondary prevention, disease overlap is a high-risk situation.

How might this impact on clinical practice?

- A careful follow-up is needed in patients with disease overlap. Further improvements in therapeutic management are needed for these patients.

available for patients with these diseases and have been associated with an improved prognosis. ${ }^{1-3}$ Observational studies carried out separately for each disease have provided information on how these recommendations translate into clinical practice and on the consequences in terms of outcomes in a real-life setting. ${ }^{4-8}$ By design, these studies do not allow direct comparisons of the level of secondary prevention and/or residual risk from one disease to another. However, such data would be of interest, as this may help focus efforts on the individuals in greatest need. In addition, although patients with combined $\mathrm{CAD}$ and $\mathrm{AF}{ }^{9} \mathrm{HF}$ and $\mathrm{AF}^{10}$ or $\mathrm{HF}$ and $\mathrm{CAD}^{11}$ have been shown to be at high risk, a comprehensive assessment of the overlap between the three diseases is lacking.

To address these questions, we designed a prospective registry of outpatients with an inclusion diagnosis of $\mathrm{CAD}, \mathrm{AF}$ and/or HF. Different patient groups were formed according to all possible combinations of diagnoses. We report the level of secondary 


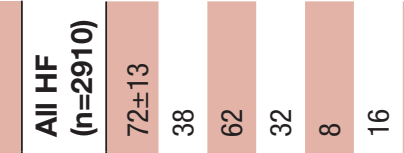

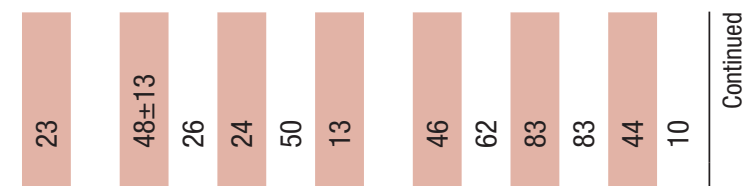

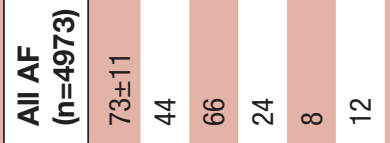

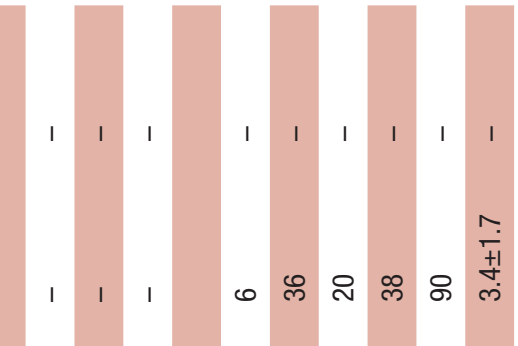

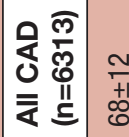

岩

岂

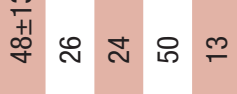

$\frac{0}{8}$
$\frac{1}{2}$
$\frac{1}{1}$
$\mathbb{D}$
$\frac{1}{7}$

这突

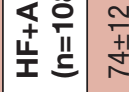

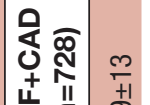

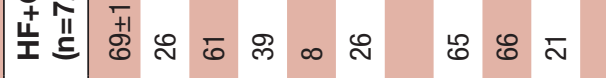

$\frac{2}{+1}$

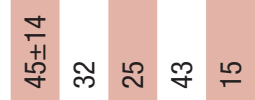

ㄴำ

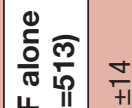

岌 站

产

这

蒙

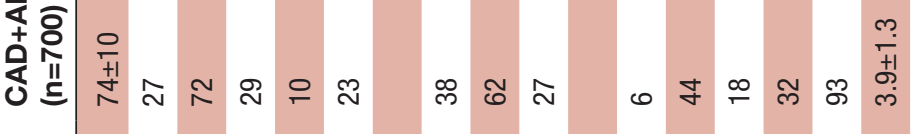

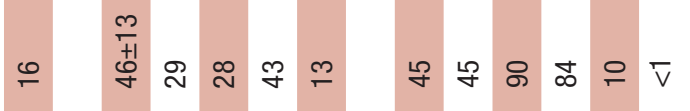

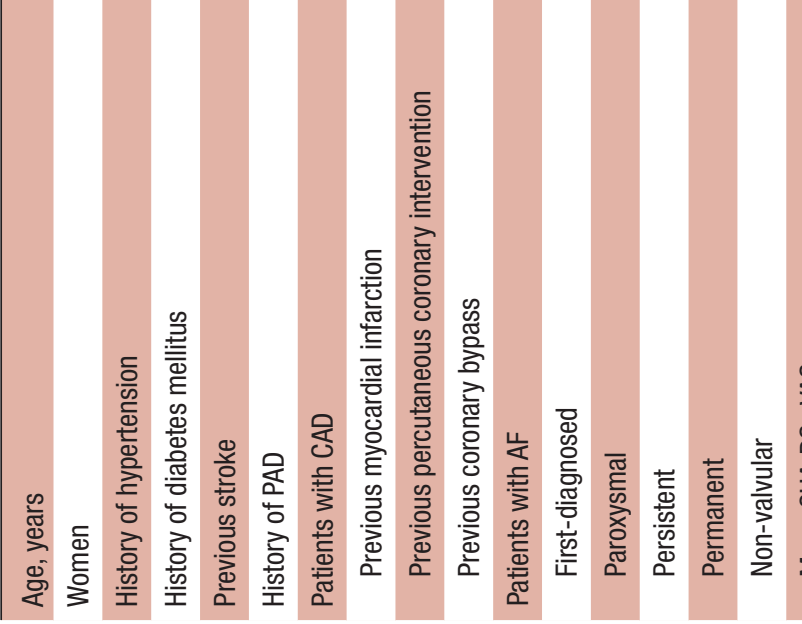




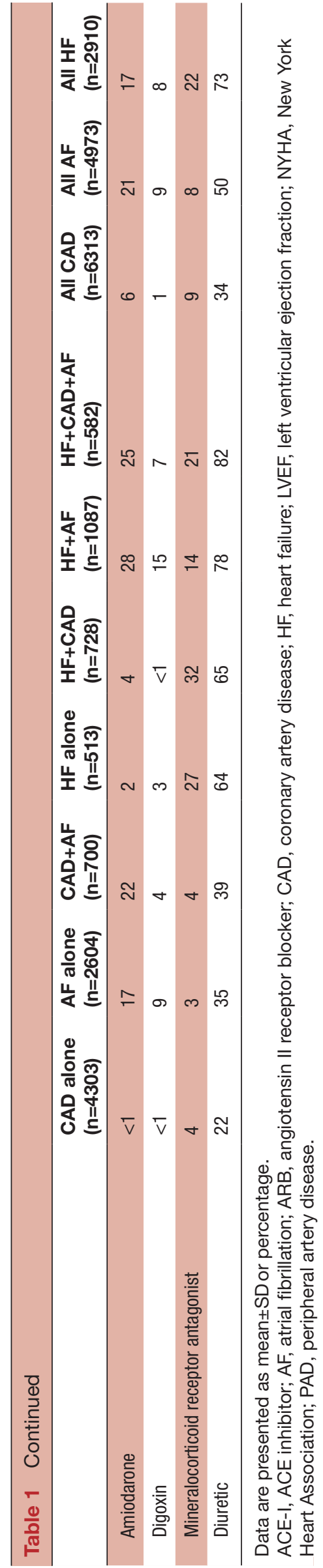

prevention according to current guidelines and allcause and cardiovascular mortality throughout a 3-year follow-up in the different groups.

\section{METHODS}

The Suivi d'une cohorte de patients présentant une pathologie CARDIaque en régiO $n$ NORd-pas-de-Calais (CARDIONOR) study was a multicentre study that enrolled 10517 outpatients with a diagnosis of $\mathrm{CAD}, \mathrm{AF}$ and/or $\mathrm{HF}$ between January 2013 and May 2015. The patients were included by 81 cardiologists from the Nord-pas-de-Calais region in France during outpatient visits. The participating physicians were selected on the basis of their geographic distribution to provide a representative sample of current cardiology practice in university, non-university and private centres in the area.

Patients were considered eligible if they met at least one of three inclusion criteria: $\mathrm{CAD}, \mathrm{AF}$ and/or HF. Documented CAD was defined as a history of myocardial infarction (MI), coronary revascularisation and/ or the presence of coronary stenosis $>50 \%$ on coronary angiogram. Documented AF was defined as a history of $\mathrm{AF}$, even if in sinus rhythm at inclusion. Documented HF was defined as a history of hospitalisation for HF and/ or a history of symptoms and signs of HF associated with echocardiographic evidence of systolic dysfunction, left ventricular hypertrophy, left atrial enlargement or diastolic dysfunction. The sole exclusion criterion was age $<18$ years. Patients with other cardiovascular or non-cardiovascular illnesses or comorbidities were not excluded. All patients consented to the study after being informed in writing of the study's objectives and treatment of the data, as well as on their rights to object, of access and of rectification.

At the initial visit, the investigators (ie, the cardiologists) prospectively completed a case record form containing information regarding demographic and clinical details

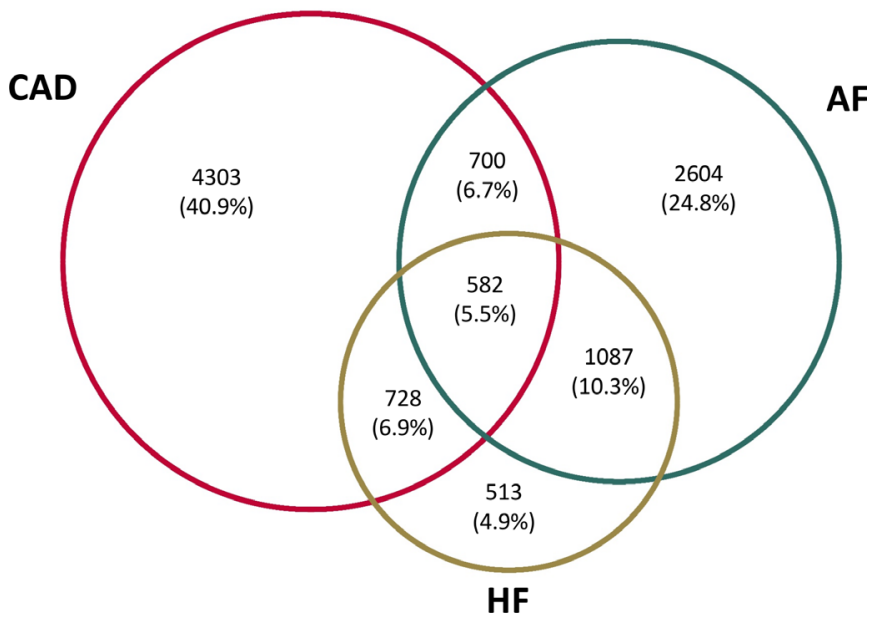

Figure 1 Venn diagram of the CARDIONOR population. AF, atrial fibrillation; CAD, coronary artery disease; CARDIONOR, Suivi d'une cohorte de patients présentant une pathologie CARDlaque en régiOn NORd-pas-de-Calais; HF, heart failure. 


\begin{tabular}{|c|c|c|c|c|c|}
\hline CAD patients & $\begin{array}{l}\text { All CAD } \\
(n=6313)\end{array}$ & $\begin{array}{l}\text { CAD alone } \\
(n=4303)\end{array}$ & $\begin{array}{l}\text { CAD+AF } \\
(n=700)\end{array}$ & $\begin{array}{l}\text { HF+CAD } \\
(n=728)\end{array}$ & $\begin{array}{l}H F+C A D+A F \\
(n=582)\end{array}$ \\
\hline An antithrombotic* drug for all patients with CAD & 99.0 & 99.4 reference & $\begin{array}{l}98.3 \\
p=0.017\end{array}$ & $\begin{array}{l}98.6 \\
p=0.044\end{array}$ & $\begin{array}{l}97.6 \\
p=0.001\end{array}$ \\
\hline A statin for all patients with CAD & 91.0 & 92.3 reference & $\begin{array}{l}85.6 \\
p<0.0001\end{array}$ & $\begin{array}{l}90.4 \\
p=0.106\end{array}$ & $\begin{array}{l}84.2 \\
p<0.0001\end{array}$ \\
\hline $\begin{array}{l}\text { An ACE-I or ARB for patients with CAD if presence of other } \\
\text { conditions (eg, HF, hypertension or diabetes) }\end{array}$ & 87.5 & 88.0 reference & $\begin{array}{l}84.2 \\
p=0.346\end{array}$ & $\begin{array}{l}90.8 \\
p=0.011\end{array}$ & $\begin{array}{l}84.0 \\
p=0.473\end{array}$ \\
\hline Patients with AF & $\begin{array}{l}\text { All AF } \\
(n=4973)\end{array}$ & $\begin{array}{l}\text { AF alone } \\
(n=2604)\end{array}$ & $\begin{array}{l}\text { CAD+AF } \\
(n=700)\end{array}$ & $\begin{array}{l}\mathrm{HF}+\mathrm{AF} \\
(\mathrm{n}=1087)\end{array}$ & $\begin{array}{l}\mathrm{HF}+\mathrm{CAD}+\mathrm{AF} \\
(\mathrm{n}=582)\end{array}$ \\
\hline $\begin{array}{l}\text { An oral anticoagulant for } \mathrm{AF} \text { patients with a } \mathrm{CHA}_{2} \mathrm{DS}_{2} \text {-VASc score } \\
\geq 2 \text { for men and } \geq 3 \text { for women }\end{array}$ & 81.7 & 80.9 reference & $\begin{array}{l}71.9 \\
p<0.0001\end{array}$ & $\begin{array}{l}87.8 \\
p<0.0001\end{array}$ & $\begin{array}{l}85.1 \\
p=0.015\end{array}$ \\
\hline Patients with HF & $\begin{array}{l}\text { All HF } \\
(n=2910)\end{array}$ & $\begin{array}{l}\text { HF alone } \\
(n=513)\end{array}$ & $\begin{array}{l}\mathrm{HF}+\mathrm{CAD} \\
(\mathrm{n}=728)\end{array}$ & $\begin{array}{l}\mathrm{HF}+\mathrm{AF} \\
(\mathrm{n}=1087)\end{array}$ & $\begin{array}{l}\mathrm{HF}+\mathrm{CAD}+\mathrm{AF} \\
(\mathrm{n}=582)\end{array}$ \\
\hline An ACE-I or ARB for HF patients with LVEF $<40 \%$ & 90.9 & 93.2 reference & $\begin{array}{l}93.0 \\
p=0.939\end{array}$ & $\begin{array}{l}87.3 \\
p=0.091\end{array}$ & $\begin{array}{l}89.2 \\
p=0.210\end{array}$ \\
\hline A beta-blocker for HF patients with LVEF $<40 \%$ & 91.0 & 89.8 reference & $\begin{array}{l}93.0 \\
p=0.261\end{array}$ & $\begin{array}{l}93.0 \\
p=0.314\end{array}$ & $\begin{array}{l}87.6 \\
p=0.527\end{array}$ \\
\hline An MRA for HF patients with LVEF $\leq 35 \%$ & 43.0 & 44.5 reference & $\begin{array}{l}47.8 \\
p=0.558\end{array}$ & $\begin{array}{l}36.8 \\
p=0.199\end{array}$ & $\begin{array}{l}40.5 \\
p=0.489\end{array}$ \\
\hline An ICD for HF patients with LVEF $\leq 35 \%$ & 39.9 & 31.3 reference & $\begin{array}{l}48.2 \\
p=0.002\end{array}$ & $\begin{array}{l}30.2 \\
p=0.846\end{array}$ & $\begin{array}{l}43.6 \\
p=0.033\end{array}$ \\
\hline
\end{tabular}

Data are presented as the percentage of patients actually treated according to the recommendation out of the total number of patients relevant to this recommendation. Age-adjusted and sex-adjusted $p$ values were obtained by logistic regression with the single-disease groups (CAD alone, AF alone and $\mathrm{HF}$ alone) as the references.

${ }^{*}$ Antiplatelet drug and/or oral anticoagulant.

ACE-I, ACE inhibitor; AF, atrial fibrillation; ARB, angiotensin II receptor blocker; CAD, coronary artery disease; HF, heart failure; ICD, implantable cardioverter defibrillator; LVEF, left ventricular ejection fraction; MRA, mineralocorticoid receptor antagonist.

of the patients, including current medications. A history of hypertension was defined as the patient receiving $\geq 1$ antihypertensive treatment. A history of diabetes mellitus was defined as treatment with oral antidiabetic drugs or insulin, or a previous history of elevated $(>126 \mathrm{mg} / \mathrm{dL})$ fasting blood glucose on at least two separate occasions in conjunction with ongoing dietary measures. Previous stroke included ischaemic stroke and haemorrhagic stroke. Peripheral artery disease was defined as a history of peripheral revascularisation and/or the presence of $>50 \%$ peripheral stenosis in an imaging study. Valvular AF included a history of rheumatic valvular disease or valvular surgery. Previous MI included ST-elevation MI and non-ST elevation MI. The $\mathrm{CHA}_{2} \mathrm{DS}_{2}$-VASc score was calculated for all patients with AF. The left ventricular ejection fraction (LVEF) was the most recent echocardiographic assessment. For each patient, we analysed secondary prevention according to the class I - level A recommendations of current European Society of Cardiology guidelines. ${ }^{1-3}$ For patients with CAD: (A) an antithrombotic drug (antiplatelet or anticoagulant) for all patients, (B) a statin for all patients and (C) an ACE inhibitor (ACE-I) or angiotensin II receptor blocker (ARB) in the subgroup with a LVEF $<40 \%$, diabetes mellitus or hypertension. For patients with AF: an oral anticoagulant in patients with a $\mathrm{CHA}_{2} \mathrm{DS}_{2}$-VASc score $\geq 2$ for men and $\geq 3$ for women. For patients with HF: (A) an ACE-I or ARB in the subgroup with $\mathrm{LVEF}<40 \%$, (B) a beta-blocker in the subgroup with LVEF $<40 \%$, (C) a mineralocorticoid receptor antagonist (MRA) in the subgroup with LVEF $\leq 35 \%$ and (D) an implantable cardioverter defibrillator in the subgroup with LVEF $\leq 35 \%$.

The patients were then followed up by their treating cardiologists. The number of outpatient visits was at the discretion of the treating cardiologists. Protocol-specified follow-up was performed at 3 years using a standardised case record form to report clinical events. To minimise follow-up bias, general practitioners and/or patients were contacted by a research technician in the case of missing information. The identification of patients with events for adjudication was based on interviews with patients/ relatives during outpatient visits, on discharge summaries for hospitalisation during follow-up that were sent to treating cardiologists and on information obtained by the research technician. All clinical events were adjudicated by two investigators blinded to each other. A third investigator joined the adjudication in case of disagreement according to prespecified definitions. A consensus was then reached. Cardiovascular causes of death included congestive HF, sudden death, stroke, MI, limb ischaemia, mesenteric ischaemia, aortic aneurysm, pulmonary embolism and other cardiovascular death. Non-cardiovascular causes of death included cancer, sepsis, renal failure, respiratory failure, liver failure, gastrointestinal bleeding, 

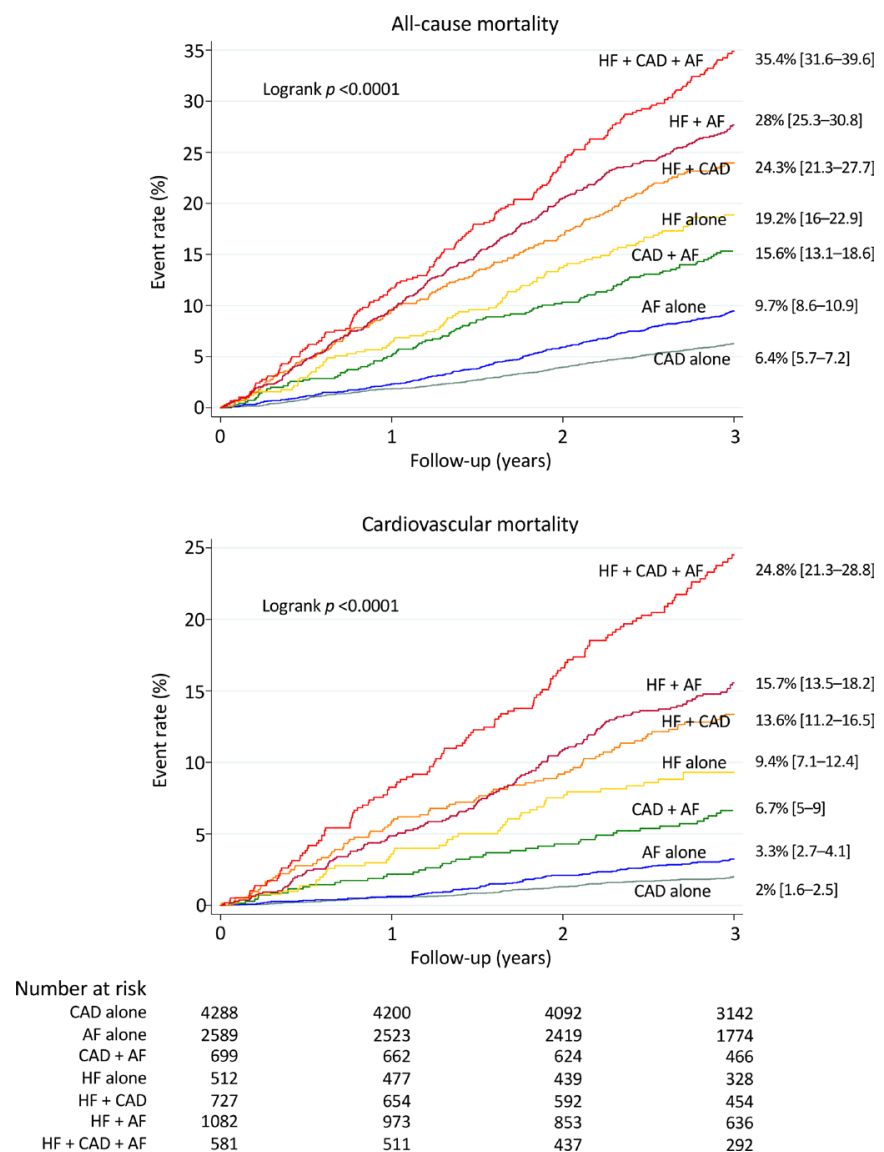

Figure 2 All-cause mortality and cardiovascular mortality rates according to diagnosis at inclusion. Kaplan-Meier curves during follow-up with unadjusted 3-year mortality rates and $95 \% \mathrm{Cls}$. $\mathrm{AF}$, atrial fibrillation; $\mathrm{CAD}$, coronary artery disease; HF, heart failure.

suicide or accident and other non-cardiovascular death. Deaths by an unknown cause were kept as a separate category. The definitions for adjudication of the causes of death were published previously. ${ }^{12}$

Continuous variables are described as mean \pm SD. Categorical variables are presented as absolute numbers and percentages. Data were analysed in the overall study population and according to diagnosis at inclusion in the study. Seven mutually exclusive diagnostic groups were formed: $\mathrm{CAD}$ alone, $\mathrm{AF}$ alone, $\mathrm{CAD}+\mathrm{AF}, \mathrm{HF}$ alone, $\mathrm{HF}+\mathrm{CAD}, \mathrm{HF}+\mathrm{AF}$ and $\mathrm{HF}+\mathrm{CAD}+\mathrm{AF}$. We also present the data in all patients with $\mathrm{CAD}$ (ie, patients with at least a diagnosis of $\mathrm{CAD}$ ), all patients with $\mathrm{AF}$ (ie, patients with at least a diagnosis of $\mathrm{AF}$ ) and all patients with $\mathrm{HF}$ (ie, patients with at least a diagnosis of HF). Because of a lack of prior similar studies, no formal power calculation was performed. It was estimated that a $>10000$ total sample size should allow comparisons among groups. Since the proportion of missing data was low $0.3 \%$ for LVEF; $<0.02 \%$ for other variables), missing variables were not imputed. Logistic regression was used to compare the levels of secondary prevention among the groups. Cumulative all-cause mortality and cardiovascular mortality rates were estimated by the Kaplan-Meier method and compared using the log-rank test. Age-adjusted and sexadjusted HRs and 95\% CIs for all-cause and cardiovascular mortality were calculated using Cox proportional hazard analyses. All-cause mortality rates were compared with the expected mortality of persons of the same age and gender in the same geographic area. Control data were obtained from the Region Nord Pas-de-Calais live tables for 2015 provided by the French Institute of Statistics. Expected and observed 3-year mortality rates were compared using $\chi^{2}$ analysis. All statistical analyses were performed using STATA V.14.2 software. Significance was assumed at $\mathrm{p}<0.05$.

\section{RESULTS}

A total of 10517 outpatients with a diagnosis of CAD, AF and/or HF were included in the CARDIONOR registry. The CARDIONOR population is summarised in Figure 1. Most patients $(70.6 \%)$ had only one disease at inclusion. In $29.4 \%$ of the cases, the patients had two or three diseases at inclusion. A total of $60 \%$ of patients had CAD (all patients with CAD), 47.3\% had AF (all patients with $\mathrm{AF}$ ) and $27.7 \%$ had HF (all patients with HF). The distribution of single disease/multiple disease was $68 \% / 32 \%$ in all patients with $\mathrm{CAD}, 52 \% / 48 \%$ in all patients with $\mathrm{AF}$ and $18 \% / 82 \%$ in all patients with HF.

The baseline characteristics of the study population according to diagnosis at inclusion are summarised in table 1 . The mean age ranged from $65 \pm 14$ years in patients with $\mathrm{HF}$ alone to $76 \pm 10$ years in patients with $\mathrm{HF}+\mathrm{CAD}+\mathrm{AF}$, and the proportion of women varied from $22 \%$ in patients with CAD alone to $51 \%$ in patients with $\mathrm{HF}+\mathrm{AF}$. The proportion of patients with diabetes varied from $19 \%$ in the $\mathrm{AF}$ alone group to $39 \%$ in the $\mathrm{HF}+\mathrm{CAD}$ group. One-half of all CAD patients had a history of $\mathrm{MI}$, and most underwent at least one coronary revascularisation procedure before inclusion (prior percutaneous coronary intervention $70 \%$, prior coronary bypass $21 \%)$. Ninety per cent of all patients with AF had nonvalvular $\mathrm{AF}$, and the most frequently observed patterns were permanent $\mathrm{AF}(38 \%)$ and paroxysmal $\mathrm{AF}(36 \%)$. The mean $\mathrm{CHA}_{2} \mathrm{DS}_{2}-\mathrm{VASc}$ score ranged from $2.8( \pm 1.5)$ in patients with $\mathrm{AF}$ alone to $5.1( \pm 1.4)$ in patients with $\mathrm{HF}+\mathrm{CAD}+\mathrm{AF}$. A quarter of all patients with $\mathrm{HF}$ were in New York Heart Association (NYHA) class 3-4, and the proportions with reduced, midrange and preserved ejection fraction $(\mathrm{EF})$ were $26 \%, 24 \%$ and $50 \%$, respectively. Table 1 lists major cardiovascular medications prescribed at inclusion according to the different subgroups.

We analysed the level of secondary medical prevention in the different subgroups according to current guidelines (table 2). Almost all patients with CAD received an antithrombotic drug, 91\% received a statin and $87.5 \%$ received an ACE-I or ARB if HF, hypertension or diabetes was present. Eighty-two per cent of AF patients with a $\mathrm{CHA}_{2} \mathrm{DS}_{2}$-VASc score $\geq 2$ for men and $\geq 3$ for women received an oral anticoagulant; this proportion was $72 \%$ in $\mathrm{AF}$ patients with a $\mathrm{CHA}_{2} \mathrm{DS}_{2}-\mathrm{VASc}$ score of 1 . Ninety-one 
All-cause mortality
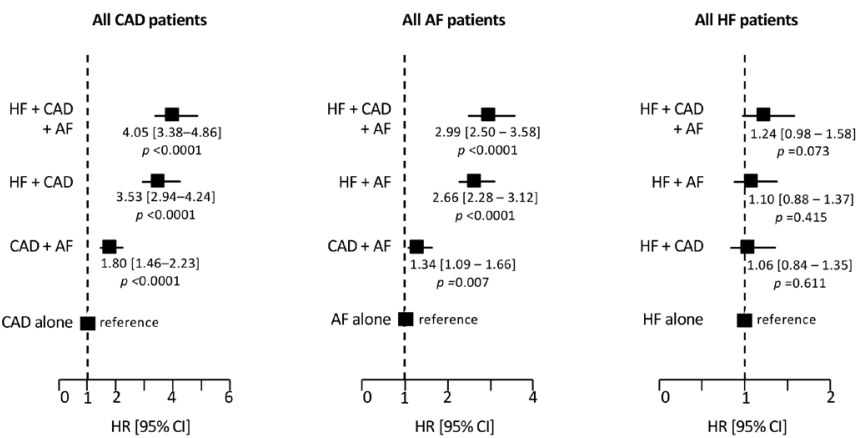

Cardiovascular mortality
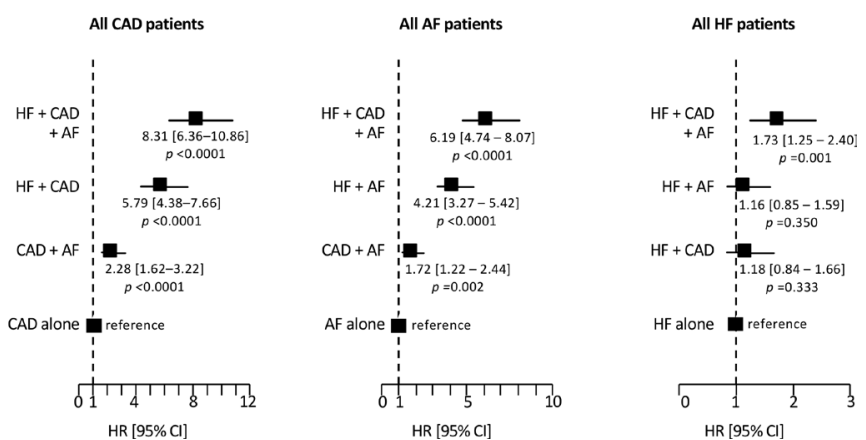

Figure 3 Age-adjusted and sex-adjusted HRs for all-cause mortality and cardiovascular mortality according to diagnosis at inclusion. Left: 6295 patients with CAD with follow-up. The CAD alone group served as the reference group. Middle: 4951 patients with AF with follow-up. The AF alone group served as the reference group. Right: $2902 \mathrm{HF}$ patients with follow-up. The HF alone group served as the reference group. AF, atrial fibrillation; CAD, coronary artery disease; $\mathrm{HF}$, heart failure.

per cent of HF patients with reduced ejection fraction received an ACE-I or ARB, and the same proportion received a beta-blocker. An MRA was prescribed in $43 \%$ of HF patients with LVEF $\leq 35 \%$, and $40 \%$ of HF patients with LVEF $\leq 35 \%$ had an ICD. The use of HF treatments according to LVEF are shown in online supplementary table S1. Table 2 shows that the presence of coexisting diseases was associated with significant differences for several recommendations. However, the overall picture was that of the adequate use of secondary prevention interventions in the different subgroups.

Clinical follow-up data were obtained for 10478 patients $(99.6 \%)$ at a median 3.2 years. There were 1581 deaths, including 713 cardiovascular deaths, 690 noncardiovascular deaths and 178 deaths from unknown causes. A detailed list of the causes of death in the different groups of patients is provided in online supplementary table S2. The 3-year all-cause mortality rate was $13.5 \%$ (95\% CI 12.9 to 14.2 ) for the overall study population, $12.2 \%$ (95\% CI 11.4 to 13.0 ) for all CAD, $17.5 \%$ (95\% CI 16.5 to 18.7 ) for all $\mathrm{AF}$ and $27 \%$ (95\% CI 25.4 to 28.7) for all HF patients. The 3-year cardiovascular mortality rate was $6.4 \%$ (95\% CI 5.9 to 6.9 ) for the overall study population, $5.9 \%$ (95\% CI 5.3 to 6.5 ) for all CAD, $8.9 \%$ (95\% CI 8.1 to 9.8) for all $\mathrm{AF}$ and $15.9 \%$ (95\% CI 14.5 to 17.3 ) for all HF patients. Figure 2 shows Kaplan-Meier curves for all-cause mortality and cardiovascular mortality in the seven mutually exclusive diagnostic groups. All-cause mortality at 3 years varied from $6.4 \%$ in the CAD alone group and $9.7 \%$ in the $\mathrm{AF}$ alone group to $35.4 \%$ in the $\mathrm{HF}+\mathrm{CAD}+\mathrm{AF}$ group. Cardiovascular mortality at 3 years varied from $2 \%$ in the $\mathrm{CAD}$ alone group and $3.3 \%$ in the $\mathrm{AF}$ alone group to $24.8 \%$ in the $\mathrm{HF}+\mathrm{CAD}+\mathrm{AF}$ group. Figure 3 shows age-adjusted and sex-adjusted HRs for allcause mortality and cardiovascular mortality according to coexisting diseases. In all patients with $\mathrm{CAD}$, risk progressively increased when $\mathrm{AF}, \mathrm{HF}$ and $\mathrm{AF}+\mathrm{HF}$ were present. Similar results were found in all patients with AF when $\mathrm{CAD}, \mathrm{HF}$ and $\mathrm{CAD}+\mathrm{HF}$ were present. In all patients with $\mathrm{HF}$, the mortality of patients with $\mathrm{HF}+\mathrm{CAD}$ and $\mathrm{HF}+\mathrm{AF}$ was similar to that of $\mathrm{HF}$ alone. In contrast, there was a trend of increased all-cause mortality and significantly increased cardiovascular mortality in patients with $\mathrm{HF}+\mathrm{CAD}+\mathrm{AF}$.

Figure 4 compares observed all-cause mortality versus age-matched and gender-matched expected allcause mortality in the different groups of patients. In the subgroups including patients with HF (HF alone, $\mathrm{HF}+\mathrm{CAD}, \mathrm{HF}+\mathrm{AF}, \mathrm{HF}+\mathrm{CAD}+\mathrm{AF}$ ), observed mortality rates were roughly two times higher than expected mortality rates $(p<0.0001$ for all comparisons). However, the observed mortality rates of patients with $\mathrm{CAD}$ alone or $\mathrm{AF}$ alone were lower than expected mortality rates $(p<0.0001$ for both comparisons). The observed mortality rate for the $\mathrm{CAD}+\mathrm{AF}$ subgroup was similar to the expected mortality rate.

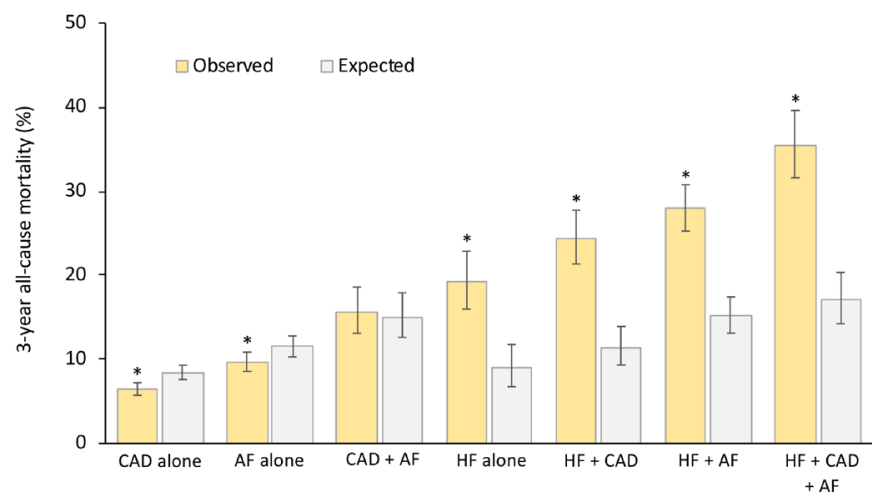

Figure 4 Observed all-cause mortality rates versus agematched and gender-matched expected all-cause mortality rates in the general population of the same geographic area. Three-year observed and expected rates with $95 \%$ Cls according to diagnosis at inclusion. ${ }^{*} \mathrm{P}<0.0001$ versus expected mortality. AF, atrial fibrillation; $C A D$, coronary artery disease; HF, heart failure. 


\section{DISCUSSION}

The present study was designed to compare secondary prevention and clinical outcome among patients with $\mathrm{CAD}, \mathrm{AF}$ and/or HF with a focus on the overlap between diseases. Due to its design (ie, prospective recruitment by the same group of investigators), our study provides information on the respective burden of CAD, AF and $\mathrm{HF}$ in an outpatient setting. Although CAD was the most frequent diagnosis, AF and HF were also reported often. In addition, our data allow the combination of diseases to be studied. Even though only one disease was mentioned in most cases, a substantial proportion of the patients had coexisting diseases, as nearly one-third of the patients combined two or three diseases.

When comparing the achieved level of secondary prevention and residual risk among common cardiovascular diseases, currently available information is from different observational studies designed as singledisease registries. ${ }^{4-8}$ Differences in inclusion periods, the geographic distribution of the patients and healthcare systems may complicate the interpretation of these analyses. In the present study, patients with CAD, AF and/ or HF were included during the same period by the same group of referent cardiologists working in a limited geographic area within the same healthcare system. Our data demonstrate a high level of secondary prevention for each disease. Thus, for the three diseases, management according to guidelines is highly feasible in routine clinical practice.

Regarding prognosis, our data underline the very high residual risk to patients with HF despite adequate secondary prevention. This is not an unexpected finding given that $\mathrm{HF}$ in itself represent a significantly worse biological substrate than CAD or AF alone. Further improvements are needed for patients with HF. Notably, the angiotensin receptor-neprilysin inhibitor LCZ696, which has been shown to be superior to ACE-Is in a subset of $\mathrm{HF}$ patients with reduced $\mathrm{HF},{ }^{13}$ was not available at the time of inclusion in the study. Moreover, the majority of patients with HF included in our registry had preserved or midrange ejection fraction, and no treatment has been shown to clearly reduce mortality in these patients. ${ }^{3}$

Although patients with multiple diseases were previously suggested to have increased risk, ${ }^{9-11}$ a study assessing all possible overlap between $\mathrm{CAD}, \mathrm{AF}$ and $\mathrm{HF}$ within the same cohort is lacking. To the best of our knowledge, our study is the first prospective registry allowing a direct comparison of secondary prevention and outcomes among groups. Although overlaps between diseases may increase the complexity of secondary prevention, we observed that evidence-based medications remained highly prescribed in patients with coexisting diseases. The increase in the number of class I - level A recommendations in these patients was not associated with important changes in the proportions of patients treated according to these recommendations. However, despite this, overlaps between diseases represent high-risk situations with incremental increases in mortality. Possible explanations include a simple addition of risks, specific mechanisms associated with unfavourable outcomes and the potential adverse impact of drug combinations. Regardless of the reasons, patients with overlapping cardiovascular diseases should be identified as high risk and selected for pronounced follow-up. In the future, it is likely that the ageing of cardiovascular populations, with an associated increase in cardiovascular disease prevalence, ${ }^{14} 15$ will further magnify this problem. Finally, the excellent outcome of patients with $\mathrm{CAD}$ or $\mathrm{AF}$ alone should be underlined. With the current level of secondary prevention, these patients have reached a level of cardiovascular risk at which future cardiovascular preventive strategies are unlikely to achieve meaningful reductions.

Our study has some limitations. First, we must acknowledge that our data reflect the practice in a regional area and that it is yet to be determined whether these findings are representative of practices in other parts of the world. Second, as inclusion was performed by cardiologists, the data may not be generalisable to the overall population in the community because of selection bias. This bias likely overestimates the extent to which these patients are managed in relation to guidelines and the reality of management, and the outcome may be worse. However, the absence of exclusion criteria and the fact that recruitment was performed in a purely outpatient setting can be considered a strength of the study. Finally, the patients were grouped according to the information available to the cardiologist at inclusion, and the study protocol did not ask for specific screening for silent coexisting diseases. Although such a strategy would certainly refine the classification, we think that our study design has the advantage of being more relevant to routine cardiology practice.

In conclusion, overlap between $\mathrm{CAD}, \mathrm{AF}$ and $\mathrm{HF}$ is relatively frequent in an outpatient setting. In modern clinical practice, secondary prevention is adequate for most patients. HF and overlap between diseases are the main drivers of mortality. Further improvements in therapeutic management are needed for these high-risk patients.

Acknowledgements Michel Deneve for monitoring the Suivi d'une cohorte de patients présentant une pathologie CARDlaque en régiOn NORd-pas-de-Calais (CARDIONOR) study.

Contributors Substantial contributions to the conception or design of the work; or the acquisition, analysis or interpretation of data for the work: all authors. Drafting the work or revising it critically for important intellectual content: all authors. Final approval of the version to be published: all authors. Agreement to be accountable for all aspects of the work in ensuring that questions related to the accuracy or integrity of any part of the work are appropriately investigated and resolved: all authors.

Funding The monitoring of the CARDIONOR study was supported by the Fondation Coeur et Recherche, Paris, France.

Competing interests NL reported personal fees from Actelion, Akcea, Amicus therapeutics, Bayer, Novartis, MSD, Pfizer, Sanofi-Aventis, and travel grants from Amgen and Bristol-Myers Squibb, outside the submitted work. GL reported personal fees from Amgen, Astra Zeneca, Bayer, Boehringer Ingelheim, Bristol-Myers Squibb, MSD, Novartis, Pfizer, Sanofi-Aventis, Servier and The Medicine Co, outside the submitted work. SN, TM, and CB had nothing to disclose. 
Patient consent for publication Not required.

Provenance and peer review Not commissioned; externally peer reviewed.

Data availability statement Data are available on reasonable request. Data are available from the corresponding author on reasonable request.

Open access This is an open access article distributed in accordance with the Creative Commons Attribution Non Commercial (CC BY-NC 4.0) license, which permits others to distribute, remix, adapt, build upon this work non-commercially, and license their derivative works on different terms, provided the original work is properly cited, appropriate credit is given, any changes made indicated, and the use is non-commercial. See: http://creativecommons.org/licenses/by-nc/4.0/.

ORCID iD

Christophe Bauters http://orcid.org/0000-0001-8268-8467

\section{REFERENCES}

1 Montalescot G, Sechtem U, Achenbach S, et al. Esc guidelines on the management of stable coronary artery disease. Eur Heart $J$ 2013;34:2949-3003.

2 Kirchhof P, Benussi S, Kotecha D, et al. 2016 ESC guidelines for the management of atrial fibrillation developed in collaboration with EACTS. Eur Heart J 2016;37:2893-962.

3 Ponikowski P, Voors AA, Anker SD, et al. 2016 ESC guidelines for the diagnosis and treatment of acute and chronic heart failure. Eur Heart J 2016;37:2129-200.

4 Bauters C, Deneve M, Tricot O, et al. Prognosis of patients with stable coronary artery disease (from the CORONOR study). Am J Cardiol 2014;113:1142-5.
5 Sorbets E, Greenlaw N, Ferrari R, et al. Rationale, design, and baseline characteristics of the CLARIFY registry of outpatients with stable coronary artery disease. Clin Cardiol 2017;40:797-806.

6 Bassand J-P, Accetta G, Camm AJ, et al. Two-Year outcomes of patients with newly diagnosed atrial fibrillation: results from GARFIELD-AF. Eur Heart J 2016;37:2882-9.

7 Bakhai A, Darius H, De Caterina R, et al. Characteristics and outcomes of atrial fibrillation patients with or without specific symptoms: results from the PREFER in AF registry. Eur Heart J Qual Care Clin Outcomes 2016;2:299-305.

8 Maggioni AP, Dahlström U, Filippatos G, et al. EURObservational research programme: regional differences and 1-year follow-up results of the heart failure pilot survey (ESC-HF pilot). Eur $J$ Heart Fail 2013;15:808-17.

9 Goto S, Bhatt DL, Röther J, et al. Prevalence, clinical profile, and cardiovascular outcomes of atrial fibrillation patients with atherothrombosis. Am Heart J 2008;156:855-63.

10 Chamberlain AM, Redfield MM, Alonso A, et al. Atrial fibrillation and mortality in heart failure: a community study. Circ Heart Fail 2011;4:740-6.

11 Felker GM, Thompson RE, Hare JM, et al. Underlying causes and long-term survival in patients with initially unexplained cardiomyopathy. N Engl J Med 2000;342:1077-84.

12 Bauters $\mathrm{C}$, Tricot $\mathrm{O}$, Meurice T, et al. Long-Term risk and predictors of cardiovascular death in stable coronary artery disease: the CORONOR study. Coron Artery Dis 2017;28:636-41.

13 McMurray JJV, Packer M, Desai AS, et al. Angiotensin-neprilysin inhibition versus enalapril in heart failure. $N$ Engl J Med 2014;371:993-1004.

14 Zoni-Berisso M, Lercari F, Carazza T, et al. Epidemiology of atrial fibrillation: European perspective. Clin Epidemiol 2014;6:213-20.

15 Roger VL. Epidemiology of heart failure. Circ Res 2013;113:646-59. 